\title{
The Simulation Modeling Research of ship Mechanical Equipment Impulse Response
}

\author{
Gu Ming, Zha Haibo, Wang Yue \\ Zhenjiang Watercraft College, Jiangsu 212003
}

Keywords: ship; Impulse response; Propulsion shafting; Simulation modeling

\begin{abstract}
With the constant development and application of computer information technology, especially in the field of computer application technology development, people's dynamics research, modeling and calculation on complex mechanical system are becoming more and more common and feasible. Based on the simulation modeling research of ship mechanical equipment impulse response, this paper mainly puts forward a kind of complex mechanical equipment dynamic response algorithm under the action of impact. In current research level in the industry, finite element method is often used because its research object is extensive, and the simulation modeling and calculation precision are relatively high. However, for concrete rigid displacement dynamics problems, it cannot meet the high quality requirements of grid and grid number, so it is very difficult to add complex dynamic boundary conditions, but also make each link more difficult in the process of modeling so as to increase the solution time. Based on the above problem, this paper takes marine complex mechanical equipment as the research object, and studies the subject by using the algorithm of dynamic impulse response.
\end{abstract}

\section{RESEARCH BACKGROUND}

Ship machinery equipment usually travels and performs the work tasks underwater. Certain reliability is generally needed under underwater explosion impulse condition. The reliability directly affects the vitality and combat effectiveness of the ship in very great degree. About research field and simulation modeling calculation method, the most commonly used ways include impact factor method, dynamic design analysis method, finite element analysis method and transfer matrix method. The most widely used is finite element method. The method has the advantages of relative low cost and convenient analysis. From the current development and application situation, it is still the main design and evaluation method of ship machinery and equipment in quite a few countries in the world. Though finite element analysis method is widely used in various fields in industry and aviation, however, it is very difficult to build a holistic finite element system model for large complex mechanical systems, especially in grid area, the grid density and the corresponding standard requirement are too high, which will likely lead to too large freedom degree, resulting in obvious increased amount of calculation. In this case, the system itself does not have the characteristics of high speed and large capacity. Eventually the simulation modeling and calculation results will have larger error phenomenon because of too coarse grid. Based on the existing finite element method, this paper puts forward a dynamic impulse response algorithm with the combination of dynamic design analysis theory, which can better handle this problem. More important is that it can more accurately reflect the nonlinear factors and multidisciplinary coupling, etc. existing in a large number of complex mechanical systems. This article here takes ship mechanical propulsion shafting, the elastomer, as focus object.

\section{THE MECHANICAL MODEL UNDER THE IMPACT OF PROPULSION SHAFTING}

\section{A. Set up model}

Here mentioned ship propulsion shafting is a typical multiple ladder support continuous elastic body, and its role in the whole ship structure frame is mainly to pass the power from the host to propeller, which makes the screw have the required thrust in the process of running, and pushes the ship forward or backward. In the propulsion shafting system framework, the basic structure consists 
of host output propeller, the propeller shaft between thrust bearing and thrust bearing, and related shaft subsidiary machinery equipment.

Propulsion shafting continuous system is an indeterminate structure and a continuous system model is used to get solution in the past practice and study. The solution impulse response is more difficult.

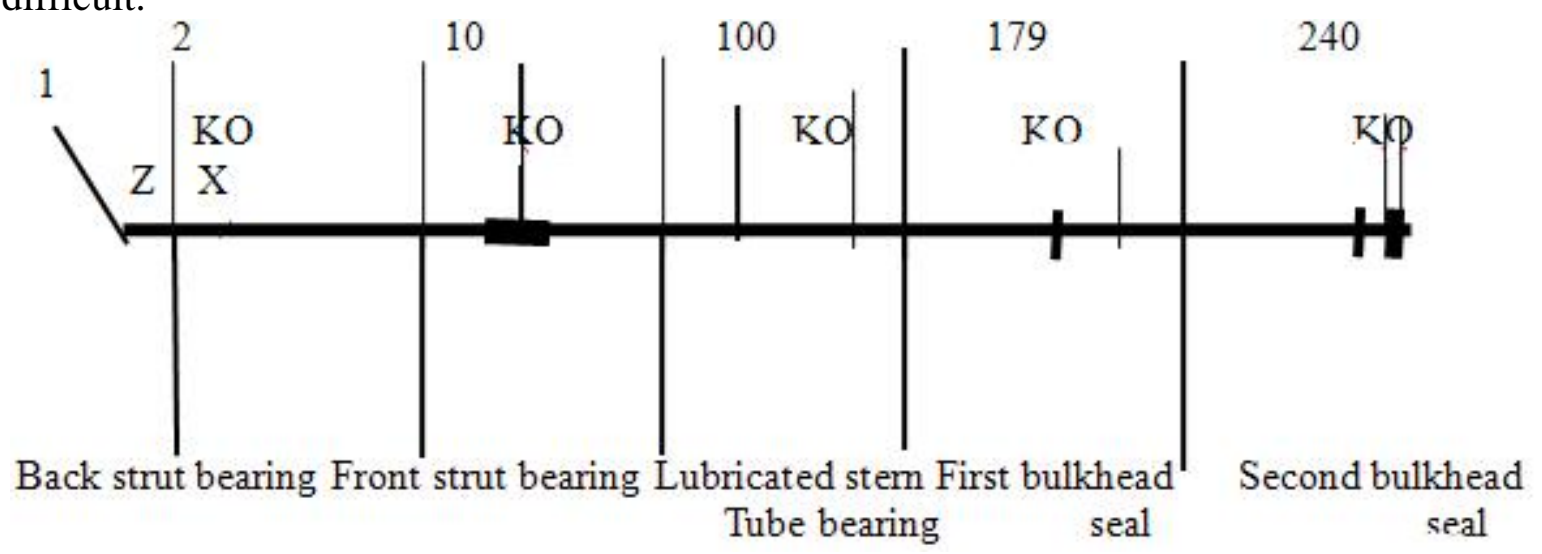

Figure 1 Propulsion shafting modeling

\section{B. Method of multi-body dynamics calculation}

Present research in the field of computational multi-body dynamics both at home and abroad has developed into soft and tough mixed multi-body system dynamics phase, and the computational multi-body dynamics is evolved from classical mechanics discipline development. In it, by using multi-body dynamics Descartes mathematical modeling approach, implement computer numerical solution and the related operations. Multi-body dynamics calculation modeling process mainly includes the following, first is initialization (start); the second step is to establish the entity model of multi-body system, and the purpose is to establish the location relationship between related artifacts; the third is to further determine the mutual constraint relationship between each component in the system, and establish appropriate constraint equation. This belongs to the middle core link, and if $\mathrm{i}$ $=1$, continue to the next step (step 4) operation, namely system boundary conditions, and establish the system's Differential Algebraic Equation; the fifth step is to use the above equations to get solution, and access to the accurate variables values of system components based on the calculation. The review section, that is step 6 , is to solve time judgment. If the set value $t i<T$, then $(i=i+1)$ goes back to the fourth step, and if the set value $\mathrm{t} i \geq \mathrm{T}$, end the process.

\section{PROPULSION SHAFTING IMPACT DISPLACEMENT CORRESPONDING NUMERICAL SIMULATION METHOD}

The corresponding calculation process of propulsion shafting impact involves the following two aspects of main contents: one is displacement response, and the other is dynamic response. So-called displacement response specifically means shafting impact structure system, and displacement response of any location (or units) produced under impact load excitation, which is dedicated to the verification of the key components within the system structure, and verifies if it is beyond the allowed displacement limit. The concrete numerical value is presented in the table below.

Table 1 Impulse response acceleration values

\begin{tabular}{ccc}
\hline Vertical acceleration & Lateral acceleration & Longitudinal acceleration \\
\hline $30 \mathrm{~g}$ & $30 \mathrm{~g} \times 0.5$ & $30 \mathrm{~g} \times 0.25$ \\
\hline
\end{tabular}


Table 2 The displacement value of propulsion shafting under different impact direction (mm)

\begin{tabular}{llll}
\hline \multicolumn{1}{c}{ Impact direction } & node & maximum & displacen \\
& & \\
The impact under vertical direction & 86 & 7.081 \\
The impact under transverse direction & 86 & 3.014 \\
The impact under longitudinal direction & 12 & 0.82 \\
\cline { 1 - 2 } & &
\end{tabular}

Table 3 Maximum stress value of propulsion shafting under different impact direction (MPa)

\begin{tabular}{lll}
\hline Impact direction & Maximum stress unit number & \multicolumn{2}{c}{ Maximum stress } \\
\hline The impact under vertical direction & 69 nodes & 94.00 \\
The impact under transverse direction & 69 nodes & 37.40 \\
The impact under longitudinal direction & 129nodes & 0.854 \\
\hline
\end{tabular}

According to the previous set model to simulate and set the maximal displacement values (mm) and maximum support stress values (MPa) of shaft support place, which is shown in Table 4

Table 4 The maximum displacement value and stress value of the shaft support place (mm/MPa)

\begin{tabular}{|c|c|c|c|c|c|}
\hline \multirow{2}{*}{$\begin{array}{l}\text { Impact } \quad \text { Back } \\
\text { Direction bear } \\
\text { Displacement value }\end{array}$} & $\begin{array}{l}\mathrm{k} \text { strut } \\
\text { aring }\end{array}$ & \multicolumn{2}{|c|}{$\begin{array}{l}\text { Front strut Lubricated stem } \\
\text { Bearing Tube bearing }\end{array}$} & \multirow[t]{2}{*}{ Middle bearing 1} & Middle bearing 2 \\
\hline & te- & & & & \\
\hline Vertical & 0.385 & 1.488 & 0.989 & 0.646 & 0.436 \\
\hline Horizontal & 0.194 & 0.517 & 0.410 & 0.324 & 0.219 \\
\hline $\begin{array}{l}\text { Longitudinal } \\
\text { Stress value }\end{array}$ & 1.616 & 1.575 & 1.243 & 1.055 & 1.083 \\
\hline Vertical & 22.083 & 27.611 & 46.600 & 26.258 & 0.670 \\
\hline Horizontal & 0.960 & 15.101 & 14.958 & 187.80 & 18.960 \\
\hline Longitudinal & 0.154 & 1.076 & 2.465 & 8.417 & 9.852 \\
\hline
\end{tabular}

\section{PROPULSION SHAFTING IMPULSE RESPONSE CALCULATION}

The impulse response link of various numerical calculations is mainly through two levels' calculation: the impact load and dynamics including impact load input and dynamics calculation. Impact load input is shown in Figure 1, in which the designed load force under vertical impact is 30 $\mathrm{g}$, while the lateral impact load is calculated on the basis of vertical impact load, which is mainly 0.5 times the vertical impact load value. According to Figure 1 model, it is $15 \mathrm{~g}$, and the longitudinal impact load value is calculated according to 0.25 times that of the vertical impact, which is $7.5 \mathrm{~g}$.

In the aspect of dynamics calculation, the details are in the following Figure 2, Figure 3 and Figure 4. The following diagram respectively shows the acceleration shock waveform of the propulsion shafting impulse response respectively on horizontal, vertical and vertical direction, and the corresponding time course data information.

The acceleration time/g 


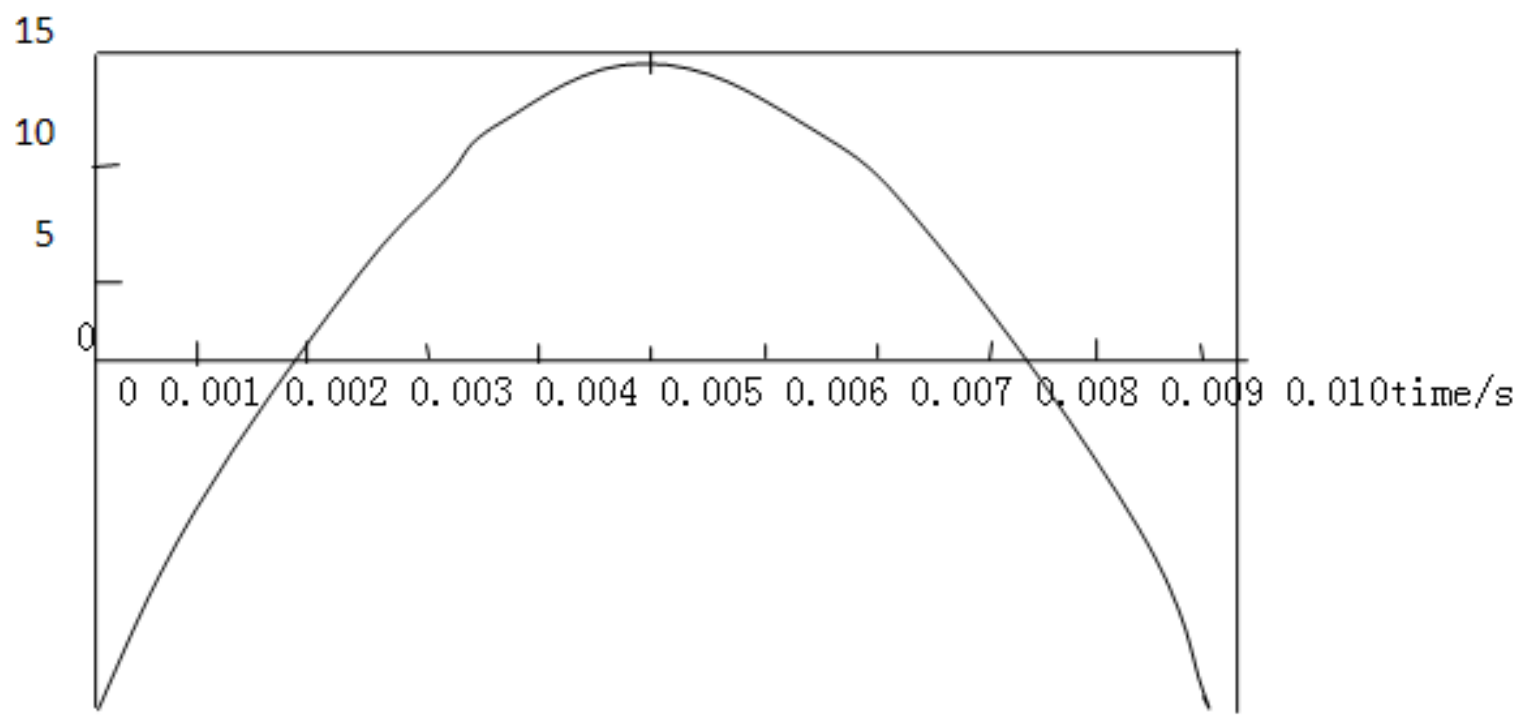

Figure 2 Lateral impact acceleration (course) relationship evolution

The acceleration time/g

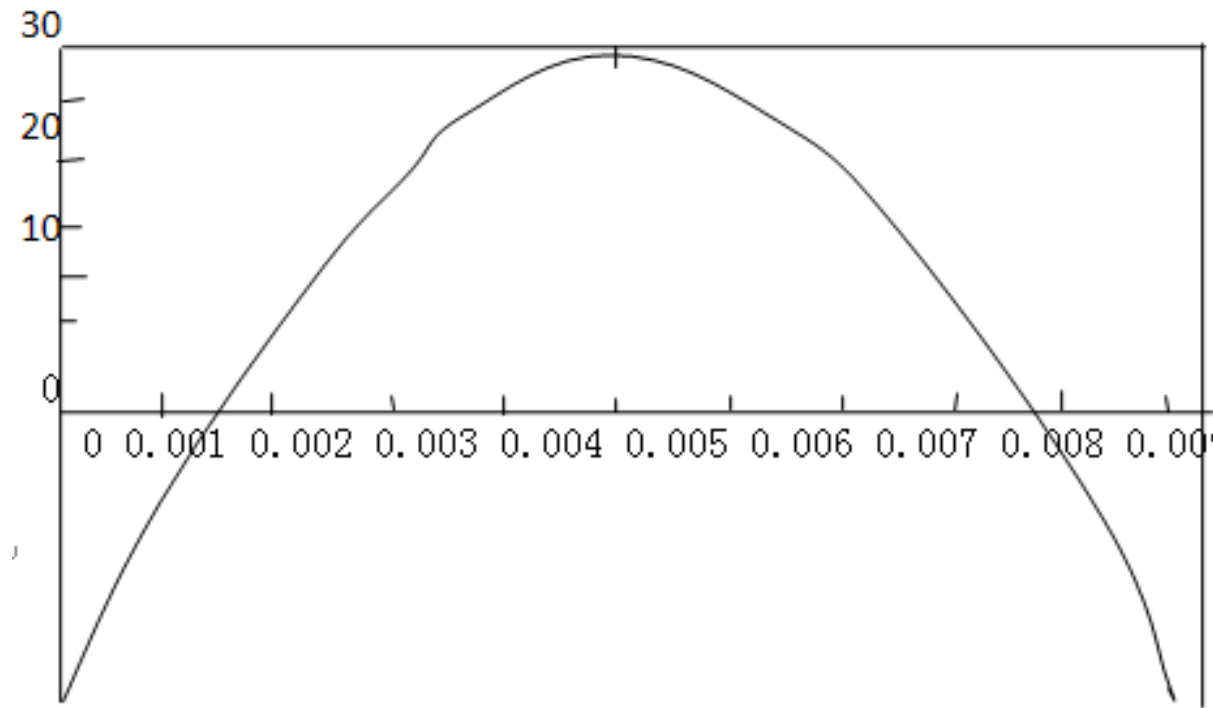

Figure 3 Vertical impact acceleration (course) relationship evolution The acceleration time/g

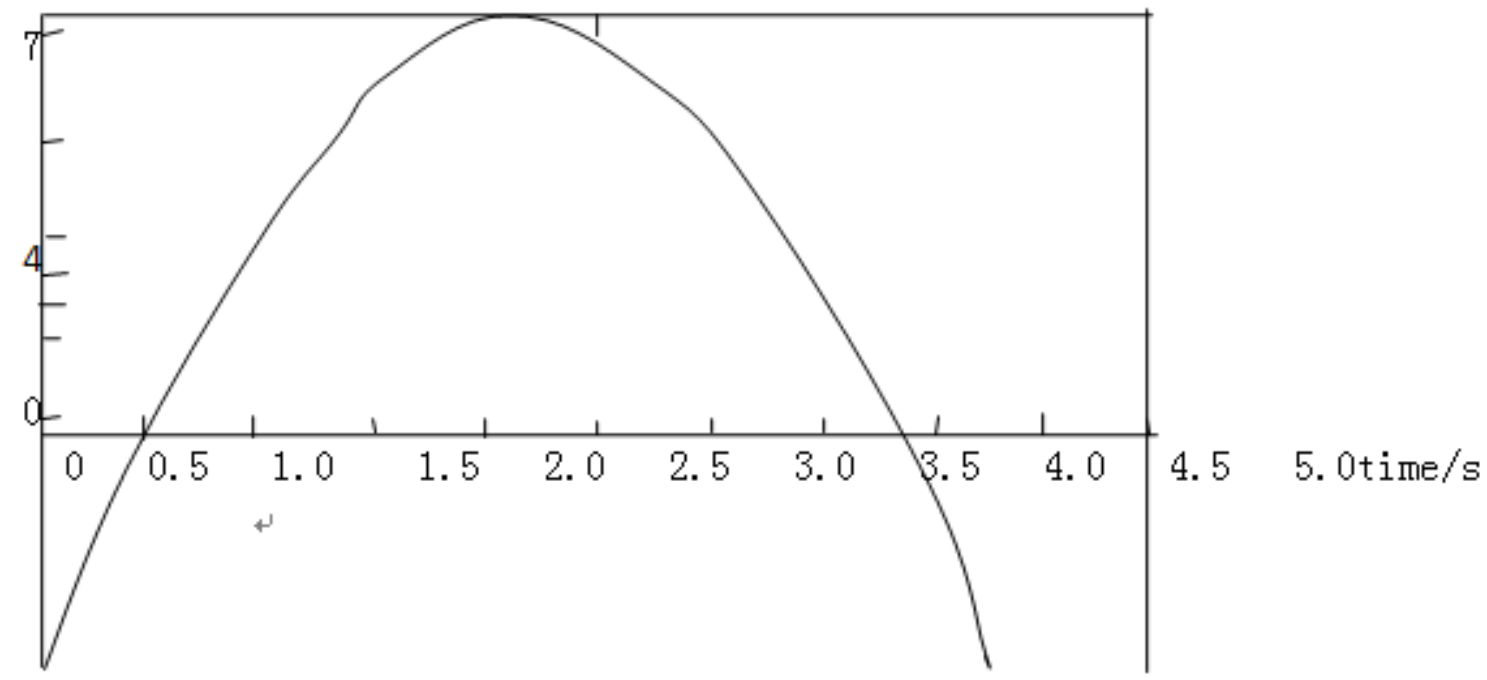

Figure 4 Longitudinal impact acceleration (course) relationship evolutions 


\section{Conclusion}

In practical applications, both for civilian ships or military ships, because part of ship shafting size is relatively large, and many related ancillary equipment, there are often cases unable to accurately complete the impact test. On the basis of the existing finite element numerical analysis method, this paper combines the corresponding dynamics, mechanics and calculation methods of multi-body dynamics and further makes simulation modeling of the main recommended shaft system in vertical impulse response. Of course, the article also mentions some corresponding conclusions which are just assumptions, and the application effect and the corresponding impulse response characteristics need further simulation calculation and checking research, but it also provides a new feasible calculation method for the future research (ship propulsion shafting impact resistance) in this field of our country.

\section{AUTHOR INTRODUCTION:}

Name date of birth: race: native: title: degree: research direction:

Gu Ming1977.9 Han Jiangsu Jiangyan lecturer master's degree mechanics performance mechanical engineering

Zha Haibo 1978.11 Han Anhui Huaining lecturer master's degree mechanical properties

Detailed address: 130 Taohuawu Road, Ship Mechanism Teaching and Research Office, Equipment Department, Zhenjiang Watercraft College, Zhenjiang, Jiangsu,

Zip code: 212003

Mobile: 13952854005

E-mail: guming77@sohu.com

\section{REFERENCES}

[1] Chu Deying, Wang Gongxian, Zhang Zhiyi. The modeling and simulation of shipboard equipment shock test system [C] Vibration Theory and Application of Academic Conferences. 2007:507-511.

[2] Qiu Yunming, Tian Yuzhong, Xiong Ting. Ship propulsion shafting torsional- the modeling and simulation of longitudinal coupling vibration [J]. Science, Technology and Engineering, 2012, 12 (30) : 8106-8110.

[3] He Shaohua, Wu Xinyue. The shipboard rotating machinery base impulse response modeling and numerical calculation [J]. Journal of Explosion and Shock, 2011, 31 (6) : 561-566.

[4] Xi Longfei, Zhang Huisheng. The modeling and simulation study of small power inland river ships petrol-electric hybrid system [J]. Mechanical and Electrical Equipment, 2014, 31 (2) : 23-27.

[5] Zhang Xiaoci. The experimental formula of surface ship equipment impulse response [J]. Journal of Ship Mechanics, 2011, 15 (7) : 791-798.

[6] Feng Linghan, Wang Yu, Du Jianye. Ship equipment impulse response calculation method equivalence research [J]. Journal of Marine Engineering, 2011(2) : - (S2) : 210-214. 